\title{
Liberdade de ensino ou escolha da família? Velho dilema, nova roupagem
}

\section{Freedom of teaching or family choice? Old dilemma, new clothes ¿Libertad de enseñanza o elección familiar? Viejo dilema, nuevo traje}

\author{
VIVIANE MERLIM MORAES \\ Departamento Sociedade, Educação e Conhecimento \\ https://orcid.org/0000-0001-6499-0558 \\ Universidade Federal Fluminense \\ Faculdade de Educação \\ Departamento Sociedade, Educação e Conhecimento \\ Niterói, RJ, Brasil
}

\begin{abstract}
Resumo: Este artigo se baseia na educação como direito público subjetivo, da Constituição Federal de 1988 ao Brasil de 2020. O avanço da direita protofascista nos pleitos de 2014 a 2018 delineou um encaminhamento da educação: a escolha da família como liberdade de ensino. Pesquisa qualitativa, com resultados parciais, apresenta a tramitação de Projetos de Lei, como os que visam à Escola Sem Partido e à possibilidade de educação domiciliar - bomeschooling - como ataques ao direito educacional e à liberdade de ensino, pondo em risco a existência da educação pública como garantia de um país democrático.
\end{abstract}

Palavras-chave: liberdade de ensino, Escola Sem Partido, educação domiciliar; protofascismo.

\begin{abstract}
This work is based on education as a subjective public right, from the Federal Constitution of 1988 to the Brazil of 2020. The rise of the proto-fascist political right in the elections from 2014 to 2018 outlined a referral to education: the family choice as freedom of teaching. It is a qualitative research with partial results that presents the progress of proposed laws, such as those that aims at School without Party and the possibility of homeschooling as attacks to the educational right and to the freedom of teaching, endangering the existence of public education as a guarantee to a democratic country.
\end{abstract}

Keywords: freedom of teaching, School without Party, homeschooling, proto fascism.

Resumen: Este articulo se basa en la educación como derecho público subjetivo, desde la Constitución Federal de 1988 hasta el Brasil de 2020. El avance de la derecha protofascista en las elecciones de 2014 a 2018 trazó un reenvio de la educación: la elección de la familia como libertad de educación. Una investigación cualitativa, con resultados parciales, presenta la tramitación de Proyectos de Ley, como los dirigidos a la Escuela Sin Partido y a la posibilidad de la educación en casa - homeschooling - como atentados al derecho educativo y a la libertad de educación, poniendo en riesgo la existencia de la educación como garantía de un país democrático.

Palabras clave: libertad de enseñanza; Escuela sin Partido, educación en casa, protofascismo. 


\section{INTRODUÇÃO}

O presente trabalho se apresenta como possibilidade de análise da realidade educacional brasileira a partir das últimas eleições, nos anos de 2014, 2016 e 2018, mais especificamente a partir do último pleito, que elegeu o presidente Jair Messias Bolsonaro. Neste período, medidas regressivas no que se refere à garantia dos direitos humanos e, por conseguinte, do direito à educação, começaram a ser intensificadas, em um movimento de afronta à lei magna. Desde a sua promulgação, fundou-se no Brasil uma inovação no campo da legislação, com a educação elevada à esfera de direito público subjetivo, o que permite que cada cidadão ou grupo organizado acione o Estado para a garantia de sua execução. A materialização de tal dispositivo se efetivou por meio da garantia de implantação e ampliação de uma rede de escolas públicas, gratuitas, laicas e pautadas na "liberdade de aprender, ensinar, pesquisar e divulgar o pensamento, a arte e o saber" e no "pluralismo de ideias e de concepções pedagógicas", conforme consta nos incisos II e III do artigo 206 da Constituição Federal (BRASIL, 1988).

Todavia, mesmo durante o processo de elaboração da constituição, ainda na Assembleia Nacional Constituinte (ANC), não havia consenso entre os deputados sobre o que de fato significava garantir o direito à educação. Em estudo anterior, analisamos o processo de tramitação do texto da educação entre as diferentes etapas do processo constituinte e concluímos que duas categorias estão diretamente associadas a tal direito, a saber: democratização das oportunidades educacionais e liberdade de ensino (MORAES, 2018). Neste texto, tomaremos como base a última delas.

Dessa forma, partimos da perspectiva de liberdade de ensino - trazida por autores como Anísio Teixeira (1968), Florestan Fernandes (1960), Luiz Antonio Cunha (2020) e Jamil Cury (2010) - para confrontar com as concepções reacionárias, que diminuem o fazer educacional ao terreno restrito da instrução neutra, em consonância com a ideologia libertariana, explicada por Luis Felipe Miguel (2018, p.19) em obra recente. Entendemos que algumas concepções que atravessaram a ANC, representadas pelo posicionamento de deputados constituintes em seus argumentos, assim como nas suas vinculações com órgãos, sindicatos e/ou associações, foram amplificadas nos últimos anos, tendo em vista todo o processo social vivido no período que desencadeou o impeachment, em 2016, assim como permitiu a eleição de um presidente com características protofascistas $^{1}$, em 2018. Destacamos, neste contexto, o espaço alcançado pelo

1 De acordo com Lyra (2020), o protofascismo se refere, em linhas gerais, aos aspectos assumidos por pessoas ou governos que se aproximam dos ideais proclamados pelo nazismo e fascismo. Possui íntima vinculação com os interesses do capital financeiro, trazendo um líder carismático com uma retórica agressiva, diferentemente do exercício da violência aberta. 
projeto Escola Sem Partido (ESP), bem como pelas propostas de educação domiciliar, ou homeschooling, como comumente é conhecida a proposta das famílias educarem seus filhos fora do aparelho escolar, domesticamente. Percebemos que ambas são estratégias de desqualificação do trabalho da escola pública, que contribuem para a intensificação de um antigo discurso que acompanha a política educacional brasileira: a transferência de recursos públicos para instituições privadas de ensino, como forma de viabilizar a liberdade de escolha das famílias a tão propagada voucherização do ensino.

Como as propostas supracitadas ainda estão em curso, os resultados são parciais. A análise foi realizada a partir de revisão bibliográfica, pesquisa em fontes primárias - atas da ANC; legislações infraconstitucionais produzidas no período 2018-2020 que abordaram a temática, - além de entrevistas.

\section{LIBERDADE DE ENSINO COMO DIREITO À EDUCAÇÃO}

A realidade específica de nosso país dificultou muito a consolidação da educação como direito. Diferentemente de muitos países saídos do pós-guerra, não vivenciamos o welfare state. Por conseguinte, o Estado não estabeleceu políticas de assistência a longo prazo, pois o capitalismo avançou em nosso país tardiamente e de maneira dependente em relação aos países centrais. Foi somente a partir dos anos de 1930 que se instaurou o Ministério da Educação, naquele momento vinculado à Saúde Pública, e algo próximo do que poderíamos finalmente chamar de política pública educacional.

Desde os reformadores, signatários do Manifesto dos pioneiros da educação nova de 1932, a escola única era vista como instituição capaz de iniciar um processo de diminuição do abismo historicamente existente entre as diferentes classes, pois as colocaria para conviver em um mesmo espaço - a escola pública. Igual para todos, com o mesmo conteúdo, laica, tal instituição seria capaz de colocar todos os alunos em situação de equidade, rompendo com a perspectiva de educação como vantagem de uns sobre os outros, alçando-a à categoria de direito. Mesmo distanciado dos valores socialistas e caracterizado pelo ideal liberal, o referido documento se constituiu em avanço para a realidade elitista e excludente brasileira. Todavia, a palavra liberdade ganhou um sentido diferenciado ao ser apropriada por grupos contrários à escola única, passando a ser atribuída à liberdade das famílias. A liberdade consistiria, sob essa visão, na possibilidade de escolha privada. 
Em suas análises sobre a efetivação do direito à educação no Brasil, Cury (2010, p. 63) discorre sobre os conflitos que historicamente puseram em lados opostos grupos católicos e positivistas, assim como entre publicistas e privatistas. Evidencia tal perspectiva na seguinte passagem²:

\begin{abstract}
A liberdade do ensino, ela nunca foi contestada no Brasil. Contestada assim, eu estou falando do ponto de vista jurídico. Tanto do ordenamento jurídico. A liberdade de ensino é a liberdade das escolas privadas. E as escolas privadas, elas são ligadas a iniciativa privada. E neste sentido elas são diretamente sustentadas pelas famílias. A liberdade de ensino, como o próprio nome diz, representa uma opção, por uma diferença que hipoteticamente a escola pública não dá. [...] Então, a liberdade de ensino, ela nem é propriamente da família, etc.
\end{abstract}

A polarização era tamanha, que à época da publicação do Manifesto, Anísio Teixeira fora considerado como defensor de "elementos agnósticos e cripto-comunistas" (BUFFA, 1979, p. 21), simplesmente pelo fato de defender a educação pública e gratuita para todos. Cabe lembrar que Anísio, assim como muitos Pioneiros, era liberal, mas a defesa da escola pública era tida, pelos privatistas e religiosos, como estatização compulsória do ensino. Disputas acirradas retardaram a promulgação da primeira Lei de Diretrizes e Bases da Educação Nacional (LDBEN no 4.024/1961), levando a formulações que colocavam a liberdade de ensino contra o monopólio estatal, defendendo-se “[...] o direito paterno de promover, com prioridade absoluta, a educação dos filhos; e dos particulares, de comunicarem a outros seus conhecimentos".

Em momentos posteriores, como na Campanha em defesa da escola pública, nos anos 1960, ou mesmo em tempos mais recentes, nos debates que permearam a ANC de 1987-1988, percebemos que os grupos - devidamente representados por alguns constituintes - e suas reivindicações por liberdade não se alteraram. O conteúdo das reivindicações se complexificou, pois novos agentes entraram no debate - o setor evangélico, que começava a crescer no país; e os representantes das escolas não confessionais, sobretudo do ensino superior, que proliferaram no período da ditadura empresarial-militar. Segue atual, portanto, a reflexão de Florestan Fernandes sobre a necessária defesa da escola pública como possibilidade de democratização da sociedade, de uma forma mais ampla (1960, p. 186):

2 Trecho da entrevista realizada para a pesquisa de doutorado, realizada no dia 24/02/2016, em Campinas, SP. 
Em primeiro lugar, o nosso objetivo central é a qualidade e a eficácia do ensino. Se defendemos a Escola Pública, fazemo-lo porque ela oferece condições mais propícias, num país, de produzir "bom ensino" e de proporcioná-lo, sem restrições econômicas, ideológicas, raciais, sociais ou religiosas, a qualquer indivíduo e a todas as camadas da população [...] Em segundo lugar, pretendemos impedir que o Estado Democrático continue prisioneiro de interesses particularistas na esfera da educação, com perda maior ou menor de sua autonomia para a realização das tarefas educacionais que lhe competem administrativamente e politicamente, e com a devastação improdutiva dos recursos oficiais destinados à educação [...] Em terceiro lugar, pretendemos esclarecer e alertar as opiniões para que todos os cidadãos patriotas e responsáveis, independentemente do seu saber e prestígio, venham a preocupar-se com os problemas educacionais brasileiros e com sua solução, colocando-se, assim, em condições de influenciar, pelos mecanismos normais do regime democrático, as decisões e orientações dos partidos e do governo nesse campo.

A carta constitucional gestada pela ANC em seus diferentes momentos - comissões e subcomissões, até a votação do texto final - embora não tenha sido tão progressista quanto sua primeira versão elaborada em diálogo com a sociedade civil organizada - subcomissão 8a, que discutia a educação, a cultura e os esportes - sinalizou que poderia ser. Apesar de incorporar algumas demandas dos movimentos, instituições e partidos que reclamavam por uma educação pública e gratuita em todos os níveis, com a elevação da educação à categoria de direito público subjetivo, deixou para trás temas fundamentais.

Temas circunscritos à liberdade do ensino, como a laicidade da escola pública, ficaram a desejar. Mesmo sendo o ensino religioso de matrícula facultativa, delegar à escola pública a tarefa de trazer a religião como disciplina obrigatória fere a separação entre as esferas pública e privada, tão necessária à configuração do Estado democrático, e, portanto, à liberdade individual quando em esferas coletivas, entendidas como espaço comum de convivência. A questão da influência religiosa - tanto dos grupos católicos, quanto dos evangélicos, sendo este último em franca ascensão no contexto brasileiro - é bem explicada por Martins (2020, p. 3), quando afirma que

[...] o significativo poder de pressão desses grupos dá visibilidade a intenção de sujeição do Estado aos interesses corporativos eclesiásticos, evidenciando uma disputa histórica entorno do entendimento do que deva ser a laicidade estatal e do consequente quinhão que advém dessa intervenção.

A discussão da laicidade reverbera na destinação exclusiva dos recursos públicos para a educação pública, uma vez que parte das escolas confessionais privadas se definiam como entidades filantrópicas, passando a fazer jus a parte destes. Tal perspectiva comprometeu o debate até então alinhavado pelos grupos 
progressistas na ANC, expressos, sobretudo, na subcomissão 8a, no momento dos depoimentos das instituições educativas ouvidas pelos parlamentares. Cunha (2018, p. 489) analisa bem tais processos em texto recente, quando revisita o processo constituinte e destaca a aliança entre setores relevantes na discussão religiosa brasileira - CNBB, AEC, $\mathrm{Abesc}^{3}$-, que ele chama da "primeira bancada evangélica da história do parlamento brasileiro” (IDEM, p. 486), e constituintes participantes das etapas de formulação por onde tramitou o texto educacional, até sua aprovação final. Aliada à questão dos recursos, tais grupos também conseguiram manter o ensino religioso nas escolas públicas, entendido como parte da formação integral dos sujeitos, desconsiderando, inclusive, o direito individual de não ter religião, posto que tal prática se circunscreve à esfera da vida privada, não devendo ser abordada em uma instituição plural, como a escola pública em uma sociedade democrática.

\section{UMA ROUPA NOVA PARA UM ANTIGO DILEMA, OU A OFENSIVA ULTRACONSERVADORA CONTRA A LIBERDADE DE ENSINO}

Concordamos com Miguel (2018, p.19) quando afirma que os anos petistas promoveram a radicalização das direitas, ou seja, das frações de classe e grupos que se mostraram atacadas pelo avanço dos direitos sociais. Tal cenário permitiu que se reciclassem três vertentes: o libertarianismo, o fundamentalismo religioso e o anticomunismo. O primeiro é ultraliberal no sentido da defesa do Estado mínimo e pela redução de todos os direitos ao da propriedade, justificando o poder político como uma rede de contatos privados; o fundamentalismo religioso cresceu no Brasil, nos anos de 1990, com o projeto de poder das igrejas (neo)pentecostais (IDEM, p. 20; MARTINS, 2020, p. 2; CUNHA, 2018, p. 486). Por fim, o anticomunismo foi retomado com a emergência dos governos com inclinações sociais na América Latina, nos anos 2000. Cabe aos nossos objetivos, pois, destacar a ideia de liberdade que voltou a ganhar espaço nas discussões, dentre elas, a educacional:

3 CNBB - Confederação Nacional de Bispos do Brasil; AEC - Associação de Educação Católica do Brasil; Abesc - Associação Brasileira de Escolas Superiores Católicas. 
A liberdade brilha como valor central das organizações libertarianas. Seus portavozes se esforçam para radicalizar temas que já estão presentes, de forma mais matizada, na tradição liberal do século XVIII em diante: a oposição imanente entre liberdade e igualdade, a igualdade como ameaça à liberdade. Esta suposta oposição se torna equivalente à distinção entre a esquerda, defensora da igualdade, e a direita, que veste as cores da liberdade. O Estado, agente caracterizado pela capacidade de impor coercitivamente suas decisões, é o oposto do mercado, terreno das trocas voluntárias e "livre", onde se realiza a "liberdade econômica" [...] Esta conceituação de "liberdade", que resume à ausência de interferência externa, é apresentado como evidente, dispensando qualquer problematização (MIGUEL, 2018, pp. 19-20).

A ofensiva ultraconservadora tomou curso na realidade brasileira, conjugando os três vieses apresentados. Combinou a eleição de um parlamento extremamente conservador em 2014, que não aceitou o resultado das eleições e promoveu, desde então, o desgaste do governo recém-eleito que redundou no impeachment da presidenta Dilma. Como consequência, promoveu-se a implantação do projeto Uma ponte para o futuro, derrotado anteriormente nas urnas e reanimado pelo vice-presidente golpista Michel Temer, em 2016.

O tom da seara educacional a partir de 2016 foi dado logo no início: o fato do ministro José Mendonça Filho receber membros de movimentos fundados por líderes empresariais reunidos no Fórum da Liberdade, em 2012 - o Movimento Brasil Livre (MBL) e o Movimento Revoltados Online. No que é pertinente ao MBL, cabe ressaltar que foi criado na onda das manifestações de 2013, com apoio financeiro de think tanks, ou seja, laboratórios de ideias de grupos de direita, brasileiros e estrangeiros, como o Atlas Network, sediado nos EUA e capilarizado em mais de 90 países (CASIMIRO, 2018, p.44). Sabemos, pois, que inexiste neutralidade na postura adotada pelo governo: seria o capital especulativo supranacional, representado por grupos empresariais, o protagonista dos encaminhamentos da educação brasileira.

Mais uma vez a tênue linha que separa a esfera privada da pública foi rompida, no caminho aberto pelo retrocesso. Com base nos votos da maioria dos ministros do Supremo Tribunal Federal (STF), em 2017, determinou-se que a aula de uma religião não se tratava de ataque à laicidade do ensino nem ao previsto na Constituição de 1988, que pressupunha o ensino de caráter confessional facultativo. Concordamos com Luiz Antonio Cunha, quando afirmou ${ }^{4}$, que

4 Trecho da entrevista para pesquisa do doutorado, realizada em 12/09/2016, no escritório do professor, no Rio de Janeiro. 
[...] a Constituição de 1988 está melhor que o da de 1891 em todos os aspectos, menos em um, sobre o ensino religioso nas escolas públicas. Ela é melhor em tudo. O casamento, não tinha o divórcio. Em [18]91, positivistas e católicos se juntaram e impediram o divórcio. Não tinha voto da mulher. Não havia garantias trabalhistas e sociais de espécie alguma. A chamada questão social não estava na Constituição de [18]91. Um monte de outras coisas não estavam, mas a de [18]91 tinha um artigo que dizia, será leigo, isto é laico, será leigo o ensino nas escolas públicas [..] A Constituição de 1988 é melhor que a de 1891 em tudo, menos nesse aspecto. Nesse aspecto ela retroagiu. Nós estamos caminhando para trás. Então tem isso, né. O processo social não é um processo unidirecional e nem linear.

A proximidade das eleições de 2018 anunciavam a necessidade de prosseguimento do golpe, uma vez que o crescimento da aceitação popular à candidatura do ex-presidente Lula ameaçava a ofensiva neoliberal em curso. Concordamos com Lodi ${ }^{5}$ quando afirma que a junção do lanfare com o Estado de exceção entrou novamente em ação no caso brasileiro, marcando uma espécie de impeachment preventivo. As fake news foram um mecanismo que auxiliou na sedimentação do terreno da campanha eleitoral de 2018. Promovido por empresas que compraram pacotes de disparos em massa de mensagens via mídias sociais, cimentaram as condições para a emergência do bolsonarismo, que angariou espaço entre amplos setores da população, com destaque para os grupos mais pobres e vinculados às igrejas neopentecostais. Usamos o conceito protofascista para definir este governo, por compreendermos que o bolsonarismo se originou como reação do próprio capital aos rumos tomados pelo capitalismo no Brasil. Concordando com Hobsbawn (1995, p.121), "Os fascistas eram os revolucionários da contrarrevolução”. Lyra (2020, p. 2) define o protofascismo da seguinte forma:

5 Aula 3 do curso "Estado de exceção e judicialização da política", ministrado pelo Prof. Dr. Ricardo Lodi Ribeiro e apresentado pelo Instituto Lula. Disponível em: <http:// https://www.youtube.com/watch? $\mathrm{v}=$ TIOhI2BPpe8\&list=PL2eR9h1Ns6FyQJRtP_gC7UDvxXU0PMv6M\&index=17\&t=920s $>$. Acesso em 15.mai. 2020 
Denomina-se protofascismo determinados aspectos sociais, políticos eideológicos do nazifascismo, que podem estar presentes, parcialmente ou na sua plenitude, conforme a situação política, inclusive na atualidade, e no Brasil. Advirta-se que o nazismo, na Alemanha, o fascismo, na Itália e o protofascismo alimentado pelo governo de extrema direita no Brasil somente se tornaram realidade em virtude do apoio decisivo - inicialmente reticente, depois entusiástico - que receberam do capital financeiro e dos políticos que representam os seus interesses, com o respaldo dos militares.

Nos três casos, esse apoio foi conquistado numa conjuntura de radicalização político-ideológica sem precedentes, quando as elites econômicas e políticas desses países entenderam que os partidos "tradicionais" (liberais de centro e de direita) poderiam não ter força suficiente para evitar o triunfo das esquerdas [...].

Com a radicalização político-ideológica promovida a partir do golpe e das eleições de 2018, acirrou-se também a tensão entre o que é pertinente à esfera pública e à privada. A questão da educação domiciliar, ou homeschooling, ganhou espaço nas discussões educacionais no Brasil - embora a legislação brasileira ainda não permita este formato de escolarização - assim como a necessidade de vigilância à instituição escolar e seus profissionais, estimulada pelo Escola Sem Partido. Dentro da ideia pervertida de liberdade reafirmada nas discussões da ANC, a possibilidade de as famílias educarem seus filhos em casa, fora do espaço escolar, visa radicalizar a possibilidade de escolha dos responsáveis neste processo, retirando as crianças e adolescentes do convívio social com seus pares e com professores no espaço das escolas, livrando-as do perigo de serem contaminadas por ideais comunistas ou pertinentes à discussão de gênero e sexualidades.

Em estudo recente, Carvalho (2020, p. 4) afirma que tanto a proposta de controle dos conteúdos escolares e da prática docente apresentada pelos projetos de lei que defendem uma escola sem partido, quanto a discussão da educação domiciliar, são resultantes de um viés neoconservador, expresso sobretudo pelo fundamentalismo cristão. Ao acentuarem a educação moral, sexual e religiosa, por meio da recusa da pluralidade ideológica e a diversidade cultural expressas no ambiente escolar, principalmente na escola pública, encontram respaldo em uma perspectiva neoliberal, que defende a liberdade de escolha educacional pelas famílias, em um visível processo de desresponsabilização estatal e de transferência de recursos públicos às instituições privados que atuam nesta área.

As propostas de educação domiciliar caminham na mesma direção do que expusemos até aqui. Não nos aprofundaremos no nascimento da proposta de homeschooling, em países ricos a partir dos anos de 1970, posto que já existem estudos com tal finalidade, como o de Carvalho (2020). Todavia, é importante salientar que cresceu em um contexto controverso, em que grupos fundamentalistas religiosos o reivindicavam como forma de garantir a autoridade familiar na educação de seus filhos, ao mesmo tempo em que libertários discutiam o papel da escola, até 
em perspectivas radicais de desescolarização da sociedade. No Brasil, no entanto, o debate se colocou de forma mais contundente no cenário público a partir de 2010, com a ANED - Associação Nacional de Educação Domiciliar.

Em sua página eletrônica, a referida associação se apresenta com a tarefa de "Promover a defesa do direito da família à Educação Domiciliar no Brasil, através da representação coletiva dos seus associados junto às autoridades, órgãos e entidades pertinentes" (ANED, 2020). Apresenta ainda os seguintes dados do que se pleiteia estabelecer como nova modalidade de ensino em nossa legislação: 7.500 famílias praticantes, perfazendo um total de 15 mil estudantes na faixa de obrigatoriedade ( 4 a 17 anos) nas 27 unidades federativas, com taxa de crescimento de adeptos de 55\% ao ano. Não explica, todavia, como tais dados foram coletados. Acreditamos, pois, que tenha sido com base no número dos novos associados. No que é pertinente aos projetos de lei já apresentados, a página eletrônica faz o seguinte resgate histórico:

Ao contrário do que muitos imaginam, a educação domiciliar é um tema recorrente no legislativo brasileiro. Para se ter uma ideia, de 1994 a 2019, nada menos que oito Projetos de Lei e uma PEC (Proposta de Emenda Constitucional) já tramitaram na Câmara dos Deputados, com vistas à regulamentação da ED ${ }^{6}(\mathrm{ANED}, 2020)$.

Foge ao escopo do presente texto analisar todas as propostas que já tramitaram, sendo apensadas, arquivadas e desarquivadas ao longo do processo legal. Destacaremos aqui as propostas mais recentes, que datam de 2012 até o momento atual. O deputado Lincoln Portela (PRB/MG) apresentou o PL n ${ }^{\circ}$ 3.179/12, com o objetivo de acrescentar um parágrafo ao artigo 23 da LDBEN de 1996, para dispor sobre a possibilidade de oferta domiciliar da educação básica. Em 2015, o deputado Eduardo Bolsonaro criou o PL no 3.261/15, que foi apensado ao anterior, tendo a deputada professora Dorinha Seabra Rezende (DEM/TO) como relatora, cujo voto foi favorável à proposta de educação domiciliar, por entender como mérito:

6 Constam no referido histórico os seguintes números de projetos, para uma possível consulta pelos interessados no tema: PL 4.657/94, PL 6.001/01, PL 6.484/02, PL 1.125/03, PL 3.518/08, PL 4.122/08, PEC 444/09, PL 3.179/12, PL 3.261/15, PLS (Projeto de Lei do Senado) 490/17, PLS 28/18 e PL 10.185/18. 
[...] admitir, sem obrigar, a possibilidade de uma diferenciação na responsabilidade pela educação básica, autorizando os sistemas de ensino a prever, em suas normas, a alternativa de que pais e tutores se responsabilizem diretamente pela condução do processo ensino/aprendizagem de crianças e jovens de suas famílias. Ressaltese novamente que o projeto especifica que deve haver diretrizes que assegurem a articulação, a supervisão e a avaliação periódica da aprendizagem pelos órgãos próprios dos sistemas de ensino (CÂMARA DOS DEPUTADOS, 2018b, p. 4).

Mais recentemente, o deputado Alan Rick (DEM/AC) apresentou o PL $\mathrm{n}^{\circ} 10.185 / 18$ para dispor sobre a possibilidade de oferta domiciliar da educação básica, que também foi apensado ao de 2012. Por fim, um projeto de lei do executivo foi protocolado em 2019, por iniciativa do Ministério da mulher, da família e dos direitos humanos, o PL n ${ }^{\circ} 2.401 / 2019$, com a finalidade de dispor sobre a educação domiciliar na educação básica, a partir da direção do ensino pelos pais e/ou responsáveis legais, a partir do entendimento de que "os pais ou os responsáveis legais têm prioridade de direito na escolha do tipo de instrução que será ministrada a seus filhos" (artigo $2^{\circ}$ ); "É plena a liberdade de opção dos pais ou dos responsáveis legais entre a educação escolar e a educação domiciliar [...]" (parágrafo $1^{\circ}$ do artigo $2^{\circ}$ ) (CÂMARA DOS DEPUTADOS, 2019a, p. 1).

Cabe ressaltar que se instaurou uma corrida pela regulamentação da educação domiciliar a partir do julgamento do recurso extraordinário 888.815 pelo STF. O resultado deixou as famílias educadoras - nomenclatura utilizada pela ANED para designar as famílias que praticam a educação domiciliar - em uma situação difícil, posto que o voto dos ministros fez referência à inexistência de regulamentação jurídica para exercício de tal prática. Dessa forma, o projeto de lei mais recente, do executivo, viria a regulamentar tal matéria, e, segundo a própria ministra Damares Alves, deveria ser apensado aos projetos que estavam sob a relatoria da deputada Dorinha, com a perspectiva de aprovação e, ainda, com a expectativa de uma medida provisória ser baixada, devido ao caráter de urgência da matéria. Até o momento, apenas a primeira situação se efetivou, em outubro de 2019.

Concordamos com Carvalho (2020, p. 22), quando afirma que a proposta de educação domiciliar é mais extrema de descentralização e privatização na educação, uma vez que retira a criança/o adolescente de um lugar de sociabilidade e o coloca exclusivamente sob a responsabilidade do núcleo familiar. Em um só lance, deslegitima-se o lugar da escola pública como primeira experiência da vida social, na qual a diversidade existe e deve ser respeitada; e a perspectiva da profissionalização docente, uma vez que retira do professor o papel de condutor do processo educativo. 
Na mesma linha de raciocínio segue o ataque ostensivo à liberdade docente e à própria escola pública como espaço de pluralidade, por meio do Escola Sem Partido (ESP), e o que ele disseminou como ideologia de gênero e doutrinação ideológica promovidas pela instituição escolar. O ESP se auto designa em sua página eletrônica como uma iniciativa conjunta que tem por objetivo coibir o "abuso da liberdade de ensinar", por compreender que "a doutrinação política e ideológica em sala de aula ofende a liberdade de consciência do estudante; afronta o princípio da neutralidade política e ideológica do Estado; e ameaça o próprio regime democrático" (ESP, 2020). Ganhou notoriedade quando passou a orientar a elaboração de projetos de lei, em 2014. A partir de então, diversas casas legislativas - em âmbito estadual e municipal - trataram de copiar o modelo do Projeto de Lei (PL) n 7.180/2014 - que visava incluir entre os princípios do ensino o respeito às convicções do aluno, de seus pais ou responsáveis, dando precedência aos valores de ordem familiar sobre a educação escolar nos aspectos relacionados à educação moral, sexual e religiosa - e, posteriormente, do PL $\mathrm{n}^{\circ}$ 867/2015, que visava instituir o Programa Escola sem Partido nas diretrizes e bases da educação nacional, obrigando as escolas a afixarem cartazes com seis tópicos, que estabelecessem os deveres dos professores (PENNA, 2018, p.110). Cabe ressaltar que as bancadas católica e evangélica do Congresso auxiliaram o processo de tramitação destes projetos, por tratarem de temas afins aos seus interesses, sobretudo por rechaçarem a discussão sobre o aborto e a diversidade de gênero.

Desde então, instaurou-se na comunidade acadêmica um debate sobre a pertinência e inconstitucionalidade de tais projetos, ao mesmo tempo que a sociedade começou um movimento de constante vigília sobre a prática docente. O ESP estimulava que os professores - a quem chamavam de doutrinadores fossem filmados e expostos; alguns alunos e responsáveis passaram a assumir uma postura de desconfiança e desrespeito com a instituição escolar, seus profissionais e com os próprios saberes escolares. Apesar de ter sido retirado do Senado no dia 20/11/2017 e apensado ao PL n ${ }^{\circ} 7.180 / 2014$ - que visava obrigar as escolas a respeitar as convicções do aluno, de seus pais ou responsáveis - há processos semelhantes em tramitação na Câmara na atualidade, como o PL n 246/2019, apresentado pela Deputada Bia Kicis (Partido da Frente Liberal/DF); e o PL n ${ }^{\circ}$ 258/2019, de autoria do deputado pastor Eurico (Patriota/PE).

O ESP configura-se como uma das estratégias atuais para desqualificar a escola pública, por meio de um discurso que coloca em xeque a ideia de liberdade de ensino e da convivência com a pluralidade de ideias como necessárias à formação integral das novas gerações. O professor, inclusive, passa a ser visto como mero instrutor, descolando sua atuação pedagógica de uma função política, de educação 
como formação humana em sentido mais amplo. Seus paladinos defendem a mera transmissão de conteúdo, objetivamente, sem a perspectiva política (e subjetiva) do professor, e da contextualização que o ato pedagógico exige (FRIGOTTO, 2017). Ora, tal raciocínio nada mais é do que uma nova roupagem do discurso apresentado desde os anos de 1940, passando pela ANC de 1987, no qual os parlamentares vinculados às alas mais conservadoras, reivindicavam a liberdade de ensino como a possibilidade de as famílias escolherem a melhor forma de educar seus filhos. A escola pública - colocada como imposição do Estado, instituição custosa e falida - deveria ser apenas mais uma alternativa, dentre outras que os responsáveis poderiam acessar: bolsa de estudos ou vouchers, subvenção estatal às escolas privadas etc.

A discussão do ESP se posiciona em um contexto geral no qual o ataque à escola pública é o principal alvo: ao incriminar os professores, busca, ao mesmo tempo, culpá-los pelos baixos índices de rendimento escolar dos alunos e por sua insuficiência nos exames nacionais e rankings - escalonamentos internacionais, tal como apontou o atual ministro da educação Milton Ribeiro, em seu discurso de posse. Dessa forma, sustentam o senso comum e requentam a ideia de que é direito dos pais buscar uma escola de qualidade para seus filhos, fora da imposição estatal pela escola pública. Não nos espanta que seus aliados estejam também nas discussões a respeito da possibilidade de desescolarização ou da educação das crianças no próprio lar - homeschooling -, dos vouchers, entre outras questões que nos atropelam cotidianamente. Resgatamos outra passagem da entrevista realizada com Luiz Antonio Cunha, já citada anteriormente, em que ele evidencia a complexidade da situação:

[...] Hoje eu vejo todo aquele programa da escola sem partido [...] porque não tinha no passado esse programa, porque se talvez tivesse naquela época talvez estaríamos imaginando coisas. Então, hoje o que é que eu sinto que é uma reação à presença do Estado na educação. Porque o Estado está acolhendo demandas seculares da sociedade [...] que hoje existe uma reclamação muito forte contra um tipo de cultura que a escola dá, e não é só a pública, também a privada com a cobertura do Estado, não é, está impondo às famílias, famílias de classe média, mas não só. Não é? Então uma reação muito forte a isso. O programa sem partido, no meu entender, surge nesse contexto. A ideia é para por alguma coisa no lugar, bota ensino religioso no lugar. Educação moral e cívica no lugar. E educação no âmbito familiar, homeschooling, em inglês. É, então tem esse aspecto que é uma coisa que está mudando muito, é uma reação contra, é uma reação da família entre aspas, porque família não age, não é? Alguém que age invocando a família, não é? E também em nome dela. [...] Então uma reação da "família" contra essa intromissão na cultura que tem direito. É, eu sinto então que essa, esse tipo de reação existiu no passado em dose muito pequena está aumentando muito. 
O que mais preocupa o conjunto dos educadores, com a abertura realizada por projetos com tais pressupostos, tem relação com o próprio conceito de liberdade. De qual ponto de vista ela é pensada, quando se estimula os alunos a vigiar e expor o professor, assim como questionar os conteúdos que podem ou não ser ensinados pela escola, desqualificando o conhecimento científico em favor de visões particulares - baseadas em valores morais, religiosos e privados, de cada núcleo familiar? Concordamos com Fernando Penna (2018, p.109), quando afirma que apesar de frágil, os argumentos do ESP são extremamente perigosos por serem de caráter fragmentado, calcado na desconfiança e no ódio aos professores (sobretudo os das redes públicas, concursados), e por perpetrarem a manipulação política por meio do terror moral, convenientemente veiculado pelas mídias e redes sociais, sobretudo sob a forma de fake news. Convém mais uma vez ressaltar a origem da perspectiva de liberdade requentada pelo ESP, nas palavras de Luiz Antonio Cunha:

\begin{abstract}
O protagonista dessa ideologia da liberdade do ensino na linha que você falou, foi a igreja católica. Não foram os protestantes, não foram os espíritas [...] Foi a igreja católica. Porque ela tinha a pretensão de ter o domínio do ensino fundamental, pelo menos até uns anos depois da primeira LDB, já não tem mais. [...] tinha essa pretensão, agora não tem mais, isso tem embasamento doutrinário complexo [...] para que isso se efetivasse era preciso que as famílias fossem detentoras, mais uma vez famílias entre aspas, detentoras desse direito de educar os filhos. E, ao Estado corresponderia, correlativamente, o dever de criar condições para que esse direito fosse exercido de fato [...] então, o Estado teria que prover recursos, direta ou indiretamente, para que eu exercesse esse direito de botar meus filhos na escola que eu quisesse, conforme a minha orientação religiosa, ideológica, sei lá, moral, qualquer coisa desse tipo. Então é esse o esquema. Esse tipo de ideia perdeu muito a força. Não sobreviveu. Eu não sei se ele será retomado agora, depois que esse programa "escola sem partido" for derrotado. No Judiciário. No Congresso e no Judiciário. Eu estou achando que vai ser. Sendo derrotado, é possível que essa orientação dessa gente, retome aquela ideologia de antes, agora em nova embalagem, dizendo "ah, é assim? Então eu quero escolher a escola que seja adequada aos meus filhos, então vocês têm que me dar bolsa de estudos, ou permitir que eu abata no imposto de renda". Sobretudo essa gente de classe média, que paga imposto de renda, coisa e tal, permitir que eu abata no imposto de renda, que eu receba de volta de você, governo, o dinheiro que eu paguei.
\end{abstract}

\title{
CONSIDERAÇÕES FINAIS
}

Com o presente estudo pudemos perceber que a história da educação brasileira é delineada por uma constante disputa por hegemonia entre duas perspectivas de educação, que, por sua vez, coadunam-se com formas distintas de ver e pensar o ser humano e a sociedade. 
Ao longo de nossa recente história democrática, com ênfase no processo constituinte de 1987, grupos se destacaram na defesa do direito à educação em uma linha mais democrática e progressista, e outros em uma posição radicalmente distinta, ou seja, por um viés conservador e, por vezes, autoritário. O resultado deste percurso, foi uma Constituição que, ao mesmo tempo em que trouxe a inovação do direito público subjetivo, também manteve a obrigatoriedade do ensino religioso nas escolas públicas. Deixou em aberto alguns dispositivos, que deveriam ser posteriormente regulamentados, mas que, sob a força da ofensiva neoliberal que se seguiu à sua aprovação, foram esquecidos ou sobrepassados - o regime de colaboração entre os entes federados e a gestão democrática são exemplos claros.

Diante do exposto, acreditamos que as últimas décadas tem nos levado a um cenário não muito favorável em termos da consolidação do direito à educação e, por conseguinte, da liberdade de ensino em toda a sua essência - pluralidade de visões de mundo, formação crítica, liberdade nas formas e métodos de ensinar e aprender, respeito à diversidade e aos diretos humanos. No período em que vivemos com governos alinhavados ao discurso da esquerda, fomentou-se a valorização dos profissionais da educação e da ampliação das possibilidades escolares, compreendendo a educação como um sistema, no qual se deve investir em todos os níveis e modalidades, para além do que deseja o capital. Neste sentido, concordamos com Mészaros (2008), quando afirma que, para que possamos construir uma educação realmente emancipadora, devemos romper com os interesses mercantis, que buscam destruir direitos e adestrar seres.

O contexto atual, especificamente a partir dos três últimos pleitos, que resultaram na emergência do bolsonarismo, apresenta-nos um discurso que traz a escola pública e o fazer docente em uma perspectiva contra hegemônica, no qual a pluralidade de ideias e a liberdade de expressar as diferentes formas de ver e pensar o mundo são tidas como doutrinação, cabendo às famílias tradicionais pouparem as novas gerações de desvios, por meio da inculcação de princípios morais, muitas vezes fundados em uma perspectiva fundamentalista religiosa e sem comprovação científica. Tanto a proibição de conteúdos e de discussões propostas pelos projetos de lei que se alinhavam ao ESP, quanto a perspectiva da educação domiciliar caminham nesta lógica.

Urge o debate sobre a atualidade da educação brasileira para não permitir que o protofascismo siga em seu curso, no qual figuras como 
Hitler, Mussolini, diversos tiranetes e também Bolsonaro têm mais uma característica que os aparenta: elegeram os "comunistas" como inimigo comum, atribuindo-se, no Brasil, essa pecha a boa parte de opositores, que de comunistas não têm nada a ver. Por fim, os líderes fascistas e protofascistas compartilham um maniqueísmo entranhado pois entendem que só os que comungam com os seus ideais querem o bem do país. A pátria, acreditam, só é amada por eles e por seus seguidores (LYRA, 2020, p. 4).

Dessa forma, ao elegerem as instituições escolares, os profissionais da educação e o conhecimento científico como inimigos que devem ser combatidos, afirmam que nestes espaços deve habitar um pensamento único, pautado pela neutralidade, que bem afirmou Paulo Freire em muitas de suas obras e ao longo de sua militância, não existir. Talvez, por esta razão, ele mesmo tenha sido escolhido como o protótipo do intelectual a ser combatido, por meio de difamação e linchamento público, por pessoas que, na maior parte das vezes, desconhecem o debate educacional de nosso país.

Nos dias atuais, em meio a uma das piores crises de nossa história posto que amalgama questões sanitárias gravíssimas, decorrentes da pandemia da COVID-19, com uma retração econômica em níveis altíssimos - somos desafiados a pensar nos anos vindouros. Ou entendemos - como país - a ameaça que o pensamento neoconservador nos costumes e neoliberal na atuação do Estado representa para o nosso futuro, ou seguimos no rumo delineado pelos interesses do capital internacional em sua fase especulativa atual.

\section{REFERÊNCIAS}

ANED. Associação Nacional de Educação Domiciliar. Disponível em: https://www.aned.org.br/. Acesso em: 01.nov.2020.

ANTUNES, Marcello. A ponte para o futuro é, na verdade, uma pinguela rumo ao atraso do Brasil. PT Senado, 2016. Disponível em: https://ptnosenado.org. br/a-ponte-para-o-futuro-e-na-verdade-uma-pinguela-rumo-ao-atraso/ Acesso em: 25 set. 2020.

BRASIL. Constituição da república federativa do Brasil de 1988. [1988]. Disponível em: http://www.planalto.gov.br/ccivil_03/constituicao/constituicao. htm. Acesso em 08 mar. 2020. 
CÂMARA DOS DEPUTADOS. PL $\mathbf{n}^{\mathbf{0}} \mathbf{3 . 1 7 9 / 2 0 1 2}$. Acrescenta parágrafo ao art. 23 da Lei $\mathrm{n}^{\circ}$ 9.394, de 1996, para dispor sobre a possibilidade de oferta domiciliar da educação básica. [2012]. Disponível em: https://www.camara. leg.br/proposicoesWeb/prop_mostrarintegra?codteor $=963755 \&$ filename $=$ PL+3179/2012. Acesso em: 14.set.2020.

PL no 3.261/2015. Autoriza o ensino domiciliar na educação básica, formada pela educação infantil, ensino fundamental e ensino médio para os menores de 18 (dezoito) anos, altera dispositivos da Lei $\mathrm{n}^{\circ}$ 9.394, de 20 de dezembro de 1996, e da Lei no 8.069, de 13 de julho de 1990. [2015a]. Disponível em: https://www.camara.leg.br/proposicoesWeb/prop_mostrarinte gra?codteor $=1397655 \&$ filename $=$ PL+3261 $/ 2015$. Acesso em: 14. set.2020.

PL $\mathbf{n}^{\mathbf{0}} \mathbf{1 0 . 1 8 5 / 2 0 1 8 . ~ A l t e r a ~ a ~ L e i ~} \mathrm{n}^{\circ}$ 9.394, de 1996 e a Lei $n^{\circ}$ 8.069, de 1990, para dispor sobre a possibilidade de oferta domiciliar da educação básica [2018a]. Disponível em: https://www.camara. leg.br/proposicoesWeb/prop_mostrarintegra?codteor $=1671126 \&$ filename $=$ PL+10185/2018. Acesso em: 18.set.2020c.

PL n $\mathbf{n}^{\circ}$ 2.401/2019. Dispõe sobre o exercício do direito à educação domiciliar, altera a Lei no 8.069, de 13 de julho de 1990, e a Lei $\mathrm{n}^{\circ}$ 9.394, de 20 de dezembro de 1996. [2019a]. Disponível em: https://www. camara.leg.br/proposicoesWeb/prop_mostrarintegra?codteor $=1734553 \&$ filena $m e=P L+2401 / 2019$. Acesso em 20.set.2020.

PL $\mathbf{n}^{\circ}$ 7.180/2014. Altera o art. $3^{\circ}$ da Lei $\mathrm{n}^{\circ}$ 9.394, de 20 de dezembro de 1996. [2014]. Disponível em: https://www.camara. leg.br/proposicoesWeb/prop_mostrarintegra?codteor $=1230836 \&$ filename $=$ Tra mitacao-PL+7180/2014. Acesso em 20.out.2020.

PL $\mathrm{n}^{\circ}$ 867/2015. Inclui entre diretrizes e bases da educação nacional, o "Programa Escola sem Partido". [2015b]. Disponível em: https://www.camara.leg.br/proposicoesWeb/fichadetramitacao?idProposic $\mathrm{ao}=1050668$. Acesso em: 13.out.2020. 
PL n ${ }^{\circ}$ 246/2019. Institui o Programa Escola sem Partido. [2019b]. Disponível em: https://www.camara.leg.br/proposicoesWeb/ prop_mostrarintegra;jsessionid=B19AC9D610C496C4E19C7FDCC9E4 5E9C.proposicoes WebExterno2? codteor $=1719071 \&$ filename $=$ Avulso + PL+246/2019. Acesso em 08 mar. 2020.

PL $\mathbf{n}^{\mathbf{0}}$ 258/2019. Dispõe sobre o direito dos alunos de aprender sem ideologia político-partidária; sobre a conduta dos professores na transmissão dos conteúdos e acrescenta inciso XIV e parágrafo único ao art. $3^{\circ}$ da Lei no 9.394, de 20 de dezembro de 1996. [2019c]. Disponível em: https://www.camara.leg.br/proposicoesWeb/prop_mostrarintegra?codteor $=1707056 \&$ filename $=$ Tramitacao-PL+258/2019. Acesso em: 14.out.2020.

Parecer da Relatora. Deputada Professora Dorinha Seabra Rezende, pela aprovação do PL 3261/2015 e do PL 10185/2018. [2018b]. Disponível em: https://www.camara.leg.br/proposicoesWeb/prop_ mostrarintegra? codteor $=1686663 \&$ filename $=\mathrm{CVO}+2+\mathrm{CE}+\% 3 \mathrm{D} \% 3 \mathrm{E}+$ PL+3179/2012. Acesso em: 20.out.2020.

BUFFA, E. Ideologias em conflito: Escola pública e escola privada. São Paulo: Cortez \& Moraes, 1979.

CASIMIRO, Flavio Henrique Calheiros. As classes dominantes e a nova direita no Brasil contemporâneo. In: GALLEGO. E.S. (org.). O ódio como política. A reinvenção das direitas no Brasil. São Paulo: Boitempo, 2018, pp. 40- 46.

CARVALHO, M. E. P. de. Da família na escola à escola no lar: notas sobre uma polêmica. In: Revista Roteiro, v.45, p. 1-28, jan./dez. 2020. Disponível em: https://portalperiodicos.unoesc.edu.br/roteiro. Acesso em: 13.jun.2020.

CUNHA, L.A. Educação laica na constituinte. In: Revista Retratos da Escola, Brasília, v. 12, n. 24, p. 481-494, nov./dez. 2018. Disponível em: <http//www. esforce.org.br> Acesso em: 20.mai.2020.

CURY, C.R.J. Carlos Roberto Jamil Cury, intelectual e educador. Organização e introdução Cynthia Greive Veiga. Belo Horizonte: Autêntica Editora, 2010 (Coleção Perfis da Educação). 
ESP. Movimento Escola Sem Partido. Disponível em: https://www. escolasempartido.org/. Acesso em 23.abr.2020.

FERNANDES, F. Objetivos da Campanha em defesa da escola pública. In: BARROS, Roque Spencer Maciel de. BARROS, Roque Spencer de. Diretrizes e Bases da Educação. São Paulo: Pioneira, 1960.

FRIGOTTO, G. A gênese das teses do Escola sem Partido: esfinge e ovo de serpente que ameaçam a sociedade e a educação. In: FRIGOTTO, Gaudêncio (org.). Escola "sem" partido. Esfinge que ameaça a educação e a sociedade brasileira. Rio de Janeiro: UERJ, LPP, 2017, pp. 17-34).

HOBSBAWN, E. A era dos extremos. O breve século XX. 1914-1991. 2a ed. São Paulo: Companhia das Letras, 1995.

LYRA, R.P. O protofascismo brasileiro. In: Carta Maior. Disponível em: https://www.cartamaior.com.br/?/Editoria/Antifascismo/O-protofascismobrasileiro/47/47000. Acesso em 20.jul.2020.

MARTINS, A. A. Duas igrejas (o pentecostalismo) e a constituição do comum na escola. 2020. Mimeo.

MÉSZÁROS, I. A educação para além do capital. 2 ed. São Paulo: Boitempo, 2008.

MIGUEL, Luis Felipe. A reemergência da direita no Brasil. In: GALLEGO, Esther Solano (org.). O ódio como política. A reinvenção das direitas no Brasil. São Paulo: Boitempo, 2018, pp.17-26.

MORAES, Viviane Merlim. O direito à educação no campo político brasileiro: disputas ideológicas na elaboração da Constituição Federal de 1988. Tese (doutorado). Universidade Federal Fluminense, Niterói, 2018.

PENNA, Fernando. O discurso reacionário da defesa de uma "escola sem partido". In: GALLEGO, Esther Solano (org.). O ódio como política. A reinvenção das direitas no Brasil. São Paulo: Boitempo, 2018, pp. 109-114.

TEIXEIRA, Anísio. Educação é um direito. 4 ed. Rio de Janeiro: Editora UFRJ (coleção Anísio Teixeira; v.7; 1968). 


\section{Viviane Merlim Moraes}

Doutora em Educação pela Universidade Federal Fluminense. Professora Adjunta do Departamento Sociedade, Educação e Conhecimento da Faculdade de Educação da UFF, na área de Organização do Trabalho na Escola. E-mail: vivimerlim@gmail.com

Recebido em: 04/11/2020

Aceito em: 23/02/2021 